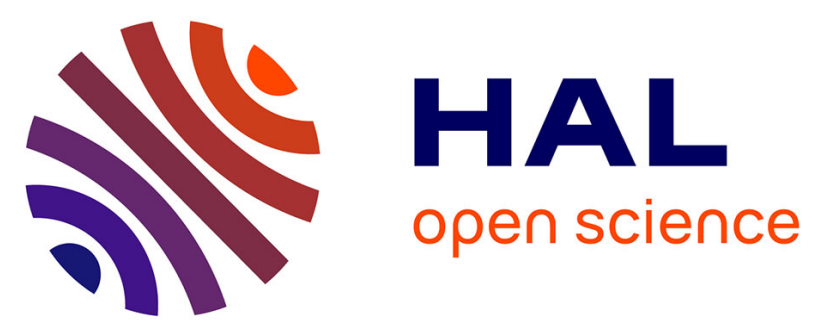

\title{
Compact optical frequency comb source based on a DFB butt-coupled to a silicon nitride microring
}

\author{
Sylvain Boust, Houssein El Dirani, François Duport, Laurène Youssef, \\ Yannick Robert, Larrue Alexandre, Camille Petit-Etienne, Eric Vinet, \\ Sébastien Kerdiles, Erwine Pargon, et al.
}

\section{To cite this version:}

Sylvain Boust, Houssein El Dirani, François Duport, Laurène Youssef, Yannick Robert, et al.. Compact optical frequency comb source based on a DFB butt-coupled to a silicon nitride microring. 2019 IEEE International Topical Meeting on Microwave Photonics , 2019, 2019 International Topical Meeting on Microwave Photonics (MWP), 10.1109/MWP.2019.8892102 . hal-02324813

\section{HAL Id: hal-02324813 \\ https: / hal.univ-grenoble-alpes.fr/hal-02324813}

Submitted on 8 Dec 2020

HAL is a multi-disciplinary open access archive for the deposit and dissemination of scientific research documents, whether they are published or not. The documents may come from teaching and research institutions in France or abroad, or from public or private research centers.
L'archive ouverte pluridisciplinaire HAL, est destinée au dépôt et à la diffusion de documents scientifiques de niveau recherche, publiés ou non, émanant des établissements d'enseignement et de recherche français ou étrangers, des laboratoires publics ou privés. 


\title{
Compact optical frequency comb source based on a DFB butt-coupled to a silicon nitride microring
}

\author{
Sylvain Boust ${ }^{1,4,}{ }^{*}$, Houssein El Dirani ${ }^{2}$, François Duport ${ }^{1}$, Laurene Youssef ${ }^{3}$, Yannick Robert ${ }^{1}$, Alexandre Larrue ${ }^{1}$, \\ Camille Petit-Etienne ${ }^{3}$, Eric Vinet ${ }^{1}$, Sébastien Kerdiles ${ }^{2}$, Erwine Parfon ${ }^{3}$, Michaël Faugeron ${ }^{1, * *}$, Marc Vallet ${ }^{4}$, \\ Corrado Sciancalepore ${ }^{2}$, Frédéric van Dijk $^{1}$ \\ ${ }^{1}$ III-V Lab, a joint laboratory between Nokia Bells France, Thales Research and Technology France and CEA-LETI, 91767 \\ Palaiseau, France \\ ${ }^{2}$ Univ. Grenoble Alpes, CEA-Leti, 38000 Grenoble, France \\ ${ }^{3}$ Univ. Grenoble Alpes, CNRS, LTM, 38000 Grenoble, France \\ ${ }^{4}$ Univ. Rennes, CNRS, Institut FOTON - UMR 6082, 35000 Rennes, France \\ *sylvain.boust@3-5lab.fr
}

\begin{abstract}
We demonstrate an integrated Kerr frequency comb source based on the butt coupling between a III-V DFB laser and a silicon nitride $\left(\mathrm{Si}_{3} \mathrm{~N}_{4}\right)$ microresonator. The 30-dB bandwidth of the optical comb is measured to be $148.7 \mathrm{~nm}$ $(18 \mathrm{THz})$, centered at $1576 \mathrm{~nm}$, which is, to the best of our knowledge, the largest ever measured on an ultra-compact source. This hybrid compact source can also be used for soliton investigations.
\end{abstract}

Keywords-Optical frequency comb, photonic integrated circuits, silicon nitride, semiconductor lasers

\section{INTRODUCTION}

Optical frequency comb sources are key elements in a growing number of applications, such as optical metrology, optical clocks [1], ultra-fast ranging distance [2] or multiplexing in photonic communications [3]. While these demonstrations started on voluminous setups with low efficiency, the rapid progress in integrated photonic platforms has significantly boosted the interest and the research about compact comb sources. Broad spectra can be produced by Kerr-comb generation in high quality whispering gallery mode resonator [4] or microresonator [5], [6]. In this paper, we present a highly compact comb source. Our passive microresonator is pumped with a continuous single mode DFB laser, on a cavity mode which generates a Kerr frequency comb through parametric four-wave mixing [7]. Nonlinear effect is possible at a low power in $\mathrm{Si}_{3} \mathrm{~N}_{4}$ thanks to its significant nonlinear refractive index (compared to silica) and its ultra-low loss allowing very high-quality factor for the microresonator [8]. The silicon nitride circuit used in our experiment are fabricated on 8-inch complementary metal oxide semiconductor (CMOS) pilot lines using a tailored subtractive process [6], [9] ensuring a void-free technology regarding the bus to microring coupling region. Moreover, an annealing step is applied to reduce the propagation losses across the $\mathrm{C}$ band occurring due to $\mathrm{N}-\mathrm{H}$ bonds overtone absorption picking at $1519 \mathrm{~nm}$.

**: M. Faugeron is now with Thales Alenia Space, 31100 Toulouse, France.
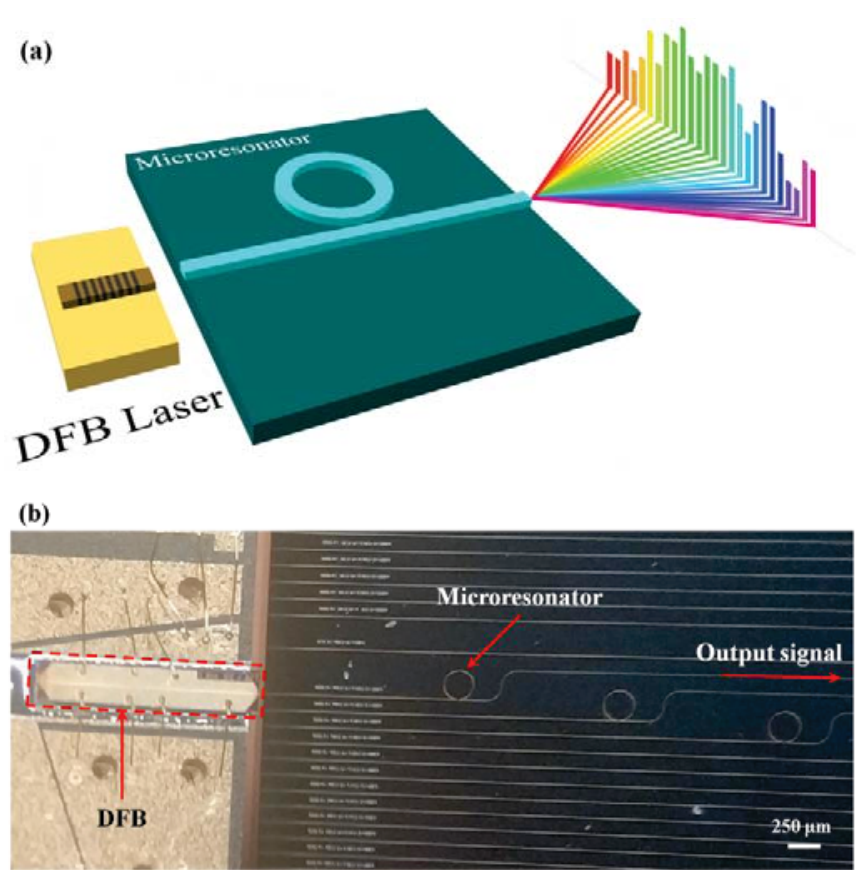

Fig. 1 a) Schematic of optical frequency comb generation by pumping the nonlinear microresonator with the DFB laser. b) Photograph of the buttcoupling. The output signal is extracted with a lens fiber at the right of the passive waveguide (not visible on the picture). The two components are independent, and by the translation of the passive chip, multiple configurations of ring microresonators can be easily tested.

\section{HIGH POWER DFB LASER}

The InP/InGaAsP DFB laser is designed to guarantee a single-mode lasing able to provide a sufficient pomp power (Fig. 2) for the generation of an optical comb in the ring resonator. The DFB laser is fabricated using a dual channel shallow ridge structure as described in [10]. The laser cavity length is $1.75 \mathrm{~mm}$. To ensure maximum output power and an optimal coupling with the passive chip, the back facet of the laser is coated to be highly reflective and the output facet antireflective. The lasing threshold is $81 \mathrm{~mA}$ and the output power ups to more than $200 \mathrm{~mW}$, as shown in Fig. 2. 


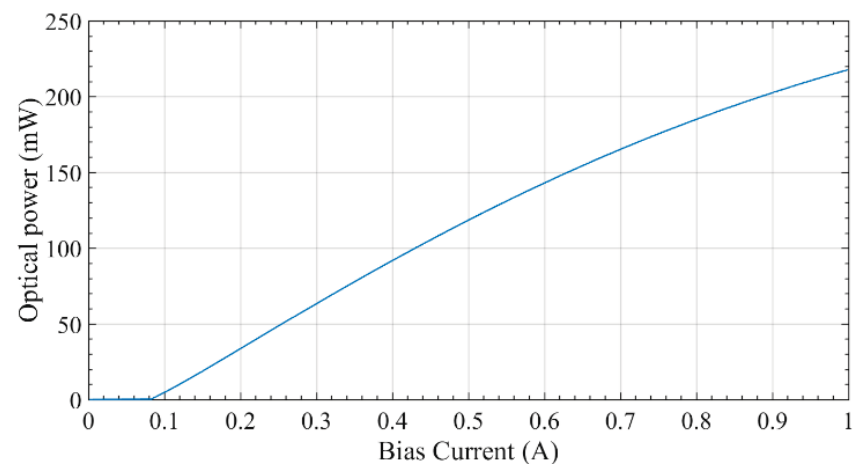

Fig. 2 Optical power measurement at $25^{\circ} \mathrm{C}$ from the DFB laser.

The laser output mode has an asymmetric shape: we measured a total angle at $1 / e^{2}$ of $20^{\circ} \times 60^{\circ}$ (horizontal $\times$ vertical). This non-circular form is due to the specific design of the laser [10]. So as to minimize the coupling loss between the laser and the passive chip, we point out that the laser divergence should be as close as possible to the divergence of the passive chip input.

The lasing wavelength can be precisely tuned by changing the bias current $(1.5 \mathrm{pm} / \mathrm{mA}$ for a temperature set around $25^{\circ} \mathrm{C}$ ), which allows an easy scan of the resonance of the microring. In Fig. 3, the measured spectrum of the laser exhibits a good side mode suppression ratio (SMSR) of $57 \mathrm{~dB}$, which circumvent possible perturbations of the frequency comb generation during the pumping of the microresonator.

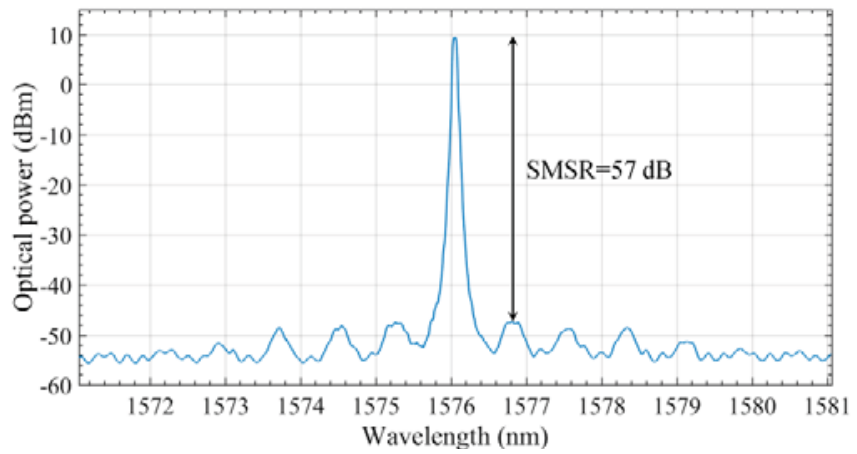

Fig. 3 Laser optical spectrum from the DFB laser chip acquired for a $823 \mathrm{~mA}$ bias current and $25.6^{\circ} \mathrm{C}$ temperature.

\section{HIGH CONFINEMENT, LOW LOSS SILICON NITRIDE RING RESONATORS}

\section{A. $\mathrm{Si}_{3} \mathrm{~N}_{4} / \mathrm{SiO}_{2}$ passive waveguide fabrication}

We start the fabrication process with a $3-\mu \mathrm{m}$-thick thermal oxidation of the $200 \mathrm{~mm}$ diameter silicon substrate to isolate the optical mode and avoid the leakage to the substrate. Then, following a tailored deposition method [6], [9], 800-nm-thick silicon nitride film $\left(\mathrm{Si}_{3} \mathrm{~N}_{4}\right)$ is deposited by low pressure chemical vapor deposition (LPCVD). A 248-nm lithography on an ASML-300 stepper is performed using 820-nm-thick resist mask with a bottom anti-reflection coating (BARC). An inductively coupled plasma (ICP) reactor is used to etch the silicon nitride film. In order to increase the photoresist selectivity, the resist is cured by applying an $\mathrm{HBr}$ plasma [11]. We used an $\mathrm{Ar} / \mathrm{Cl}_{2} / \mathrm{O}_{2}$ plasma process to open the BARC and the $\mathrm{Si}_{3} \mathrm{~N}_{4}$ is then etched with a $\mathrm{CF}_{4} / \mathrm{CHF}_{3} / \mathrm{Ar}$ plasma. The photoresist/BARC layers are removed using an $\mathrm{O}_{2}$ plasma, and $1 \%$ HF dip. The silicon nitride circuits are encapsulated by a $2-$ $\mu \mathrm{m}$-thick silica cladding layer deposited at $400^{\circ} \mathrm{C}$ using highdensity plasma-enhanced chemical vapor deposition (HDPPECVD) technique to avoid voids formation, which is one of the main causes known for devices failure. After the encapsulation, a 3-hour annealing at $1200{ }^{\circ} \mathrm{C}$ in nitrogen atmosphere is applied on the wafer to reduce the hydrogen content in the film. The propagation losses of $1.5 \mu \mathrm{m}$-wide $\times$ $800 \mathrm{~nm}$-thick waveguides are then reduced from $0.8 \mathrm{~dB} / \mathrm{cm}$ to $0.3 \mathrm{~dB} / \mathrm{cm}$ thanks to the annealing.

At the end of the process, a deep etch step has been used to form the chip facets, thus no additional facet polishing steps are required. With an atomic force microscopy (AFM), we measured a $4.5 \mathrm{~nm}$ line edge roughness (LER) on a tilted sample (Fig. 4).
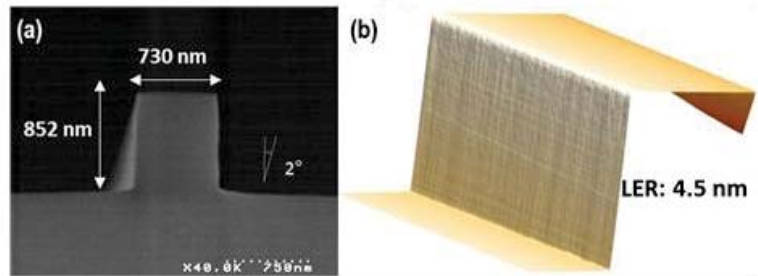

Fig. 4 a) SEM image of a $\mathrm{Si}_{3} \mathrm{~N}_{4}$ waveguide profile after subtractive patterning and $b$ ) the corresponding AFM image of the $\mathrm{Si}_{3} \mathrm{~N}_{4}$ sidewalls and the measured LER.

\section{B. $\mathrm{Si}_{3} \mathrm{~N}_{4} / \mathrm{SiO}_{2}$ chip measurements}

The microresonator used is a $\mathrm{Si}_{3} \mathrm{~N}_{4}$ ring with a $56 \mu \mathrm{m}$ radius placed at $600 \mathrm{~nm}$ of the bus waveguide, which should result in a coupling close to critical. The cross-sectional dimensions of the ring waveguide $(1.5 \mu \mathrm{m}$-wide $\times 800 \mathrm{~nm}$ thick) ensure that the dispersion is anomalous at the pump across the $\mathrm{C}$ band, which greatly eases frequency comb generation [6]. The bus waveguide is $20 \mathrm{~mm}$ long. The chip dimension is $20.0 \times 21.3 \mathrm{~mm}$. We measured the reflectivity and the transmission spectrum of the ring by using a high-resolution optical spectrum analyzer (OSA) from APEX Technologies (AP2043B model) with an integrated tunable laser source. We looked only for transverse electric (TE) resonance since the DFB laser used as pump in the next part is TE.

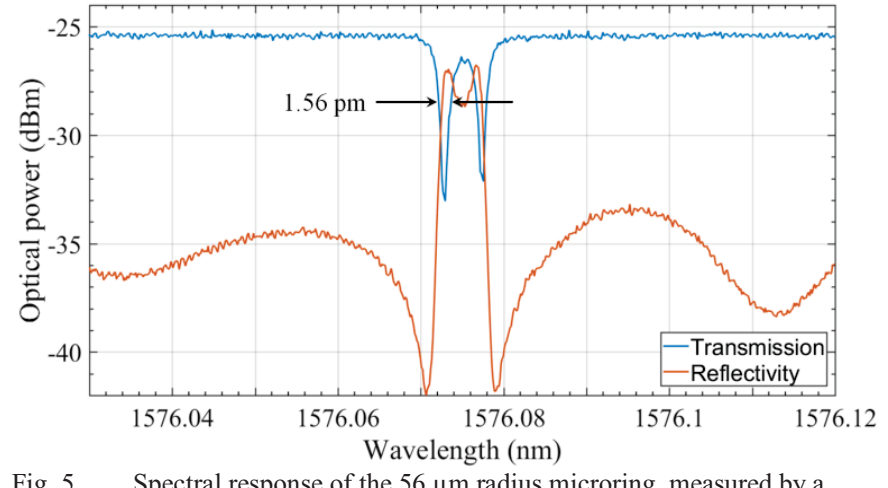

Fig. 5 Spectral response of the $56 \mu \mathrm{m}$ radius microring, measured by a 1.12 pm resolution OSA. 
The measured resonance shows a mode splitting that has been observed by other groups on this type of resonators highly confined with high quality factor [8]. Any small fabrication imperfections can easily induced a backscattering mode, leading to a splitting of the resonance as shown in Fig. 5 [12]. Both resonances have a $1.56 \mathrm{pm}(188 \mathrm{MHz})$ bandwidth, meaning a loaded quality factor $Q_{1}$ of $\sim 1 \times 10^{6}$ (thus representing an intrinsic $Q_{i}$ of $2 \times 10^{6}$ ). Note that the measured bandwidth could be overestimated (i.e., the $Q$ underestimated) due to limited resolution of the OSA. The $33 \mathrm{pm}$ local oscillation measured on the reflectivity spectrum is due to the back-end facet of the waveguide forming a parasite cavity.

By scanning widely the wavelength, we measured a $3.38 \mathrm{~nm}(408 \mathrm{GHz})$ free spectral range (FSR) of the microresonator, which determines the space between the lines generated in the frequency comb.

By injecting a test signal at the end of the passive waveguide, we measure the far-field of the passive waveguide before the microresonator. The full angle at $1 / e^{2}$ is $22^{\circ} \times 34^{\circ}$ (horizontal $\times$ vertical).

\section{HYBRID INTEGRATED OPTICAL COMB SOURCE}

\section{A. Hybrid InP-Si $\mathrm{N}_{4} / \mathrm{SiO}_{2}$ setup}

To perform the butt-coupling between the DFB laser and the passive chip (Fig. 1), we use a dynamical alignment system with micrometric translation stages. Consequently, mechanical vibrations slightly affect the performance of our device. The advantage is the possibility to easily different ring configurations.

By computing the overlap of the measured far-field from the DFB laser and the microresonator, the minimum coupling loss achievable on our setup is estimated around $0.6 \mathrm{~dB}$ to which $0.5 \mathrm{~dB}$ should be added due to the reflection at the $\mathrm{Si}_{3} \mathrm{~N}_{4}$ chip input.

\section{B. Optical comb generation}

The operating output power of the DFB laser was set at $187 \mathrm{~mW}$. However, if we subtract the coupling loss due to the mode mismatch and the propagation losses in the bus waveguide, we estimate a maximum injection power of $133 \mathrm{~mW}$. The actual injection power is lower due to alignment imperfection. By pumping the microresonator near a cavity mode, we generated an optical comb through cascaded parametric Four Wave Mixing (FWM) [7], as shown in Fig. 6.

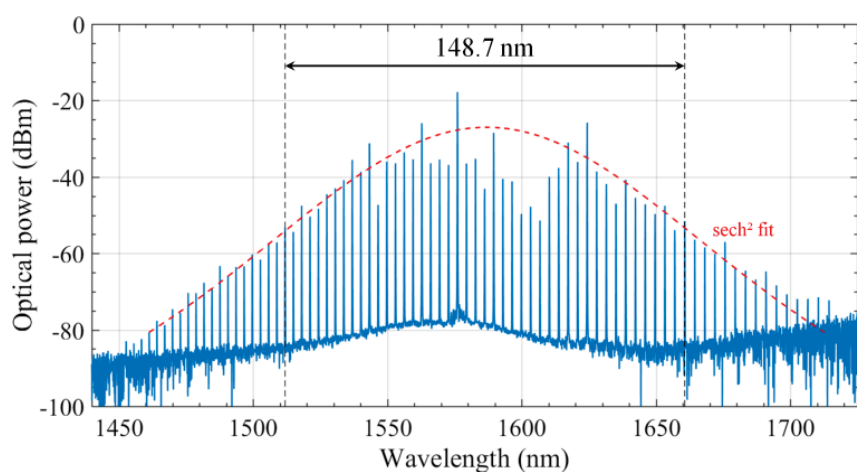

Fig. 6 Spectral measurement of an optical frequency comb generated by the pumped microresonator. The bias current of the DFB laser was $813 \mathrm{~mA}$, meaning a $187-\mathrm{mW}$ output power at $1576.08 \mathrm{~nm}$ lasing wavelength.

Here the wavelength pump laser is set at $1576.08 \mathrm{~nm}$ to match a resonance of the microresonator. The microresonator design provides anomalous group velocity dispersion [6], which greatly facilitates Kerr comb generation. As shown on Fig. 6, the 30-dB bandwidth of the Kerr comb is measured to $148.7 \mathrm{~nm}(18 \mathrm{THz})$, which is the largest value for a fully compact system to the best of our knowledge. In detail, when comparing to previous solutions, where a Fabry-Perot InP laser is butt-coupled to the silicon nitride microresonator [13], the silicon nitride circuit is air-cladded due to dispersion constraints limited by available $\mathrm{Si}_{3} \mathrm{~N}_{4}$ thickness. As a consequence, the system is harder to package and its reliability may be affected. Furthermore, in the case of the RSOA buttcoupled to the silicon nitride microresonator [14], the heater complicates the integration, while increasing the optical circuit footprint.

Our comb spectrum has a $\operatorname{sech}^{2}$ shape (see Fig. 6) that is characteristic of a single dissipative Kerr soliton (DKS) state. Others measurements [14], [15] are still necessary to prove the existence of solitons. For instance, autocorrelation and amplitude noise measurements could confirm the soliton regime.

\section{CONCLUSION}

We have developed a $\mathrm{Si}_{3} \mathrm{~N}_{4} / \mathrm{SiO}_{2}$ on silicon fabrication platform that allows the fabrication of high quality microresonator. We have demonstrated a compact optical frequency comb source formed by butt-coupling between an InP DFB laser and a $\mathrm{Si}_{3} \mathrm{~N}_{4} / \mathrm{SiO}_{2}$ microresonator. We succeed to measure a $148.7 \mathrm{~nm}(18 \mathrm{THz})$ broadband frequency comb, which is, to the best of our knowledge, the largest ever measured on an ultra-compact source. Such performance on portable systems offers the potential for a wide variety of applications relying on precise frequency comb such as metrology, communications [3] or waveform generation.

Further works will investigate the conditions of soliton's appearance by measuring different parameters such as power threshold, pump detuning, FSR frequency comb variations etc. This should enable a full control of the soliton regimes, which in turn will enable to target a large number of applications such as ultra-fast ranging distance [2] or even calibrations of astronomical spectrographs [16]. 


\section{REFERENCES}

[1] S. B. Papp et al. "Microresonator frequency comb optical clock," Optica 1, pp 10-14 (2014).

[2] P. Trocha et al, "Ultrafast optical ranging using microresonator soliton frequency combs," Science 359, pp 887-891 (2018).

[3] J. S Levy et al, "High-performance silicon-nitride-based multiplewavelength source," IEEE Photonics Technol. Lett. 24, pp 1375-1377 (2012).

[4] W. Liang, D. Eliyahu, A. B. Matsko, V. S. Ilchenko, D. Seidel, and L. Maleki, "Spectrally pure RF photonic source based on a resonant optical hyper-parametric oscillator," Proc. SPIE 8960, Laser Resonators, Microresonators, and Beam Control XVI, 896010 (2014).

[5] B. Stern, X. Ji,Y. Okawachi, A. L. Gaeta, and M Lipson, "Batteryoperated integrated frequency comb generator," Nature 562, pp 401-405 (2018).

[6] H. El Dirani, A. Kamel, M. Casale, S. Kerdiles, C. Monat, X. Letartre, M. Pu, L. K. Oxenløwe, K. Yvind, and C. Sciancalepore, "Annealingfree Si3N4 frequency combs for monolithic integration with $\mathrm{Si}$ photonics," Appl. Phys. Lett., 113, 081102 (2018).

[7] Y. K Chembo, "Kerr optical frequency combs: theory, applications and perspectives," Nanophotonics 5, pp 214-230 (2016)

[8] X. Ji et al., "Ultra-low-loss on-chip resonators with sub-milliwatt parametric oscillation threshold," Optica 4, pp 619-624 (2017).

[9] H. El Dirani, M. Casale, S. Kerdiles, C. Socquet-Clerc, X. Letartre, C. Monat, C. Sciancalepore, "Crack-Free Silicon-Nitride-on-Insulator Nonlinear Circuits for Continuum Generation in the C-Band," IEEE Photonics Technol. Lett. 30, pp. 355-358 (2018).

[10] M. Faugeron et al, "High-power tunable dilute mode DFB laser with low RIN and narrow linewidth," IEEE Photonics Technol. Lett., 25, pp 7-10 (2013).

[11] L. Azarnouche, E. Pargon, K. Menguelti, M. Fouchier, O. Joubert, P. Gouraud, C. Verove, "Benefits of plasma treatments on critical dimension control and line width roughness transfer during gate patterning" J. of Vac. Sci. and Technol. B 31, 012205 (2013).

[12] D. S. Weiss, V. Sandoghdar, J. Hare, V. Lefèvre-Seguin, J.-M. Raimond, S. Haroche, "Splitting of high-Q Mie modes induced by light backscattering in silica microspehres," Optics Letters 20, pp 1835-1837 (1995).

[13] S. A. Raja et al., "Electrically pumped photonic integrated soliton microcomb," Nature Communications 1, 680, (2019).

[14] A. L. Gaeta, M. Lipson, T. J. Kippenberg, "Photonic-chip-based frequency combs," Nature Photonics 13, pp 158-169 (2019).

[15] T. J. Kippenberg, A. L. Gaeta, M. Lipson, M. L. Gorodetsky, "Dissipative Kerr soliton in optical microresonators," Science 361, eaan8083 (2018).

[16] M.-G. Suh et al, "Searching for Exoplanets Using a Microresonator Astrocomb," Nature Photonics 13, pp 25-30 (2019). 